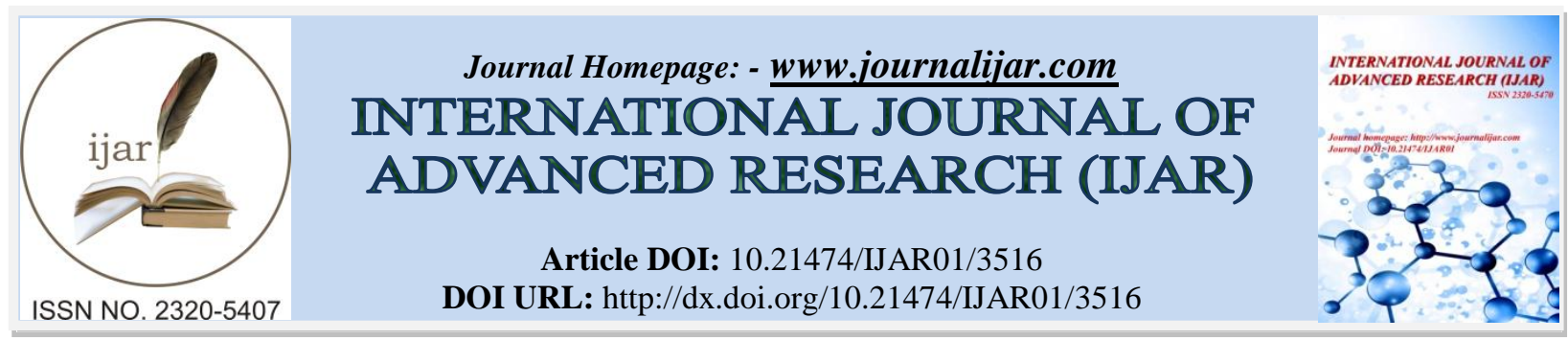

RESEARCH ARTICLE

\title{
ASSESSMENT OF PUBLIC SATISFACTION AND TREATMENT TOWARD PHC AND PUBLIC PRIVATE HOSPITAL IN EASTERN PROVINCE, KSA.
}

Hassan A. Alashwan ${ }^{1}$, Redha A. Alsaleh ${ }^{1}$, Ahmed M. alshakhs ${ }^{1}$, Mustafa S. Alfehaid ${ }^{1}$, Abdullah J. Almajed ${ }^{1}$, Huda A. Alsaleh ${ }^{1}$, Maryam K. Almumten ${ }^{1}$ and Nabil M. Kurashi ${ }^{2}$.

1. College of medicine at university of Imam abdurahman bin faisal.

2. College of medicine, department of family and community medicine, imam abdurahman bin faisal university, Saudi Arabia.

\section{Manuscript Info}

[..........................

Manuscript History

Received: 17 January 2017

Final Accepted: 18 February 2017

Published: March 2017

\section{Abstract}

Objectives:-

1. To determine the compliance and satisfaction to doctor's prescription among general population in Eastern Province of Saudi Arabia by type of health facility used, age, gender, and education.

2. To determine the reasons for non-compliance, and opinions on how to improve compliance.

Materials and Methods:-

Cross-sectional study conducted for public in eastern province. Data Collected using web-based self-administered questionnaire to fill online through newspaper, and social media like Facebook, Twitter, etc. for 6 month and periodically repeated throughout the study period, SPSS 17.0 used for data analysis. Chi-square or Fisher's Exact test used to test for statistical significance by gender, age, and education.

Background:- Compliance in healthcare is defined as the extent to which a patient's behavior coincides with the healthcare provider's recommendations for health and medical advice, we conduct unique study to involve the public instead of narrow spectrum of patient and diseases.

Results:- Total of 587 participants $62.9 \%$ were Satisfied during last visit to their physician. $32.2 \%$ stop taking medication if they feel better, $31.7 \%$ always committed to treatment. The reasons of non-compliance with medication mainly $35.6 \%$ due to large number of drugs, $28.3 \%$ due to Inappropriateness of drug, 20.8\% do not Know the function of drug. the more acuteness of illness more noncompliance, avoiding reading the patient file and lack of knowledge. More than half of participant said doctor misbehavior affect their trust about prescription. Private hospital showed to have more regular visit and satisfaction and governmental hospital showed less satisfaction. 58.8\% said that nearby health centers would not affect their compliance. $78 \%$ of the Health Centers lack communication with patient outside health facility. The best option to overcome non- compliance showed to be follow-up by social media. 
Conclusion:- Males and people at age of 30 are more compliance to drugs and more satisfied. Side effect and accumulated drugs are common cause of non-compliance, best option to overcome noncompliance are follow up by social media and explain side effects of drugs, people less satisfied with governmental hospital and more compliance to PHC so high qualified health system, patient -centered relationship, health education are needed.

Copy Right, IJAR, 2017,. All rights reserved.

\section{Introduction:-}

Compliance in healthcare is defined as the extent to which a patient's behavior (in terms of taking medication, executing the lifestyle changes, undergoing medical tests or keeping appointments with the physicians) coincides with the healthcare provider's recommendations for health and medical advice. [1] Non-compliant patients are those whose health-seeking or maintenance behaviors lack congruence with the recommendations prescribed by a healthcare provider. [2]

Patient non-compliance is a serious healthcare concern that poses a great challenge to the successful delivery of healthcare. This is widespread and has been reported from all over the world.

Previous research of specific communication variables indicates that patient-centered encounters result in: (1) the duration of the office visit remaining the same [3], [4] (2) better patient satisfaction, [5] (3) higher physician satisfaction, and (4) fewer malpractice complaints.

Medication management outcomes can be improved by adopting more client-centered approaches. To examine the implications of a client-centered relationship this reviews regarding client involvement in: (1) identifying treatment goals; (2) choosing from regimen options; (3) monitoring symptoms and evaluating regimens; and (4) self care with nonprescription pharmaceutical products. , A compliance study conducted in Saudi Arabia for those on short-term medication found $67.8 \%$ compliance.

However, compliance of patients tends to decrease with time being lower in patients on long-term medication than in those on short-term medication. [6] Another study done in Saudi Arabia found an overall 65.8\% non-compliance in patients suffering from hypertension. [7] The noncompliance to long-term therapy severely compromises the effectiveness of treatment and adversely affects the patient's condition. [8]

\section{Materials and Methods:-}

Study population and area:- Population of Eastern Province.

Study design:- Cross-sectional study

Study period:- Six months until 12-1- $1438 \mathrm{H}$

Data Collection:- Data Collected using web-based self-administered questionnaire. The information collected included demographic data, type of health facility visited, satisfaction with last visit to physician, compliance to doctor's prescription, use of medicine without doctor's prescription, questions related to reasons for noncompliance, and suggestions to improve compliance to doctor's prescription.

The public in the study area was informed about this survey (along with the web link) and requested to fill the online questionnaire through newspaper, and social media like Facebook, WhatsApp, Twitter, etc. This was periodically repeated throughout the study period

Data Analysis:- SPSS 17.0 used for data analysis. Descriptive statistics included frequency and percentages for categorical variables. Chi-square or Fisher's Exact test, as appropriate, used to test for statistical significance by gender, age, and education. The sample size using Epi info version 3 with confident level $97 \%$ is 471 . The results were expressed as mean values $\pm \mathrm{SD}$. A $\mathrm{P}$ value of $<0.05$ was considered significant. 


\section{Results:-}

Total of 587 participated in this study, $79.5 \%$ of the participants were from the Alhasa and Dammam and Qatif. Majority of participants their age Found to be between 21-30 years $(\mathrm{SD}=1.11)$ and about two third of them were females $(74.7 \%)$. All the participants were educated $(100 \%, \mathrm{n}=587)$.

The demographic characteristics of the participants are summarized in Table 1 and Geographic distribution in figure 1

Table 1:- Demographic characteristics of the study population.

\begin{tabular}{|l|l|l|}
\hline Characteristic & Number & Percentage \\
\hline Gender & & \\
Male & 148 & 25.2 \\
Female & 439 & 74.8 \\
\hline Age (Years) & 126 & \\
$\leq 20$ & 259 & 21.5 \\
$21-30$ & 103 & 44.2 \\
$31-40$ & 99 & 17.6 \\
$>40$ & & 16.9 \\
\hline Education & 126 & \\
High school or less & 461 & 21.4 \\
College or higher & & 78.5 \\
\hline Nationality & 574 & \\
Saudi & 13 & 97.8 \\
Non-Saudi & & 2.2 \\
\hline
\end{tabular}

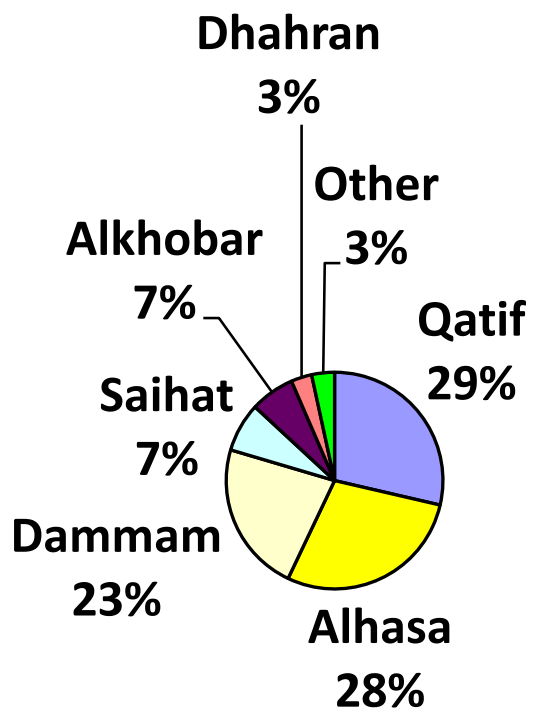

Figure 1 :Geographic distribution

According to geographic distribution as shown in figure 1, 29\% of participants from Qatif , 28\% from Alhasa , 23\% from Dammam , 7\% from Saihat , 7\% from Alkhobar, 3\% from Dhahran, 3\% others. 


\section{Figure 2:Satisfaction during last visit to the doctor by gender}

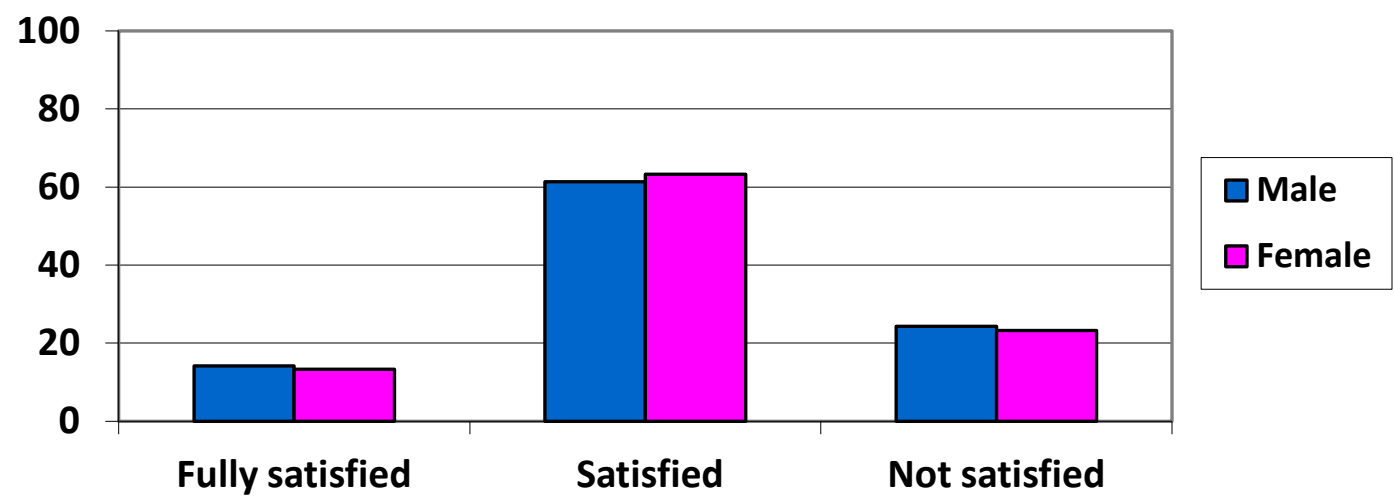

According to satisfaction during last visit to doctor by gender as shown in figure 2,

$14.18 \%$ of male and $13.34 \%$ of female are fully satisfied while 61.4 of male and 63.3 of female are satisfied and $24.32 \%$ of male and $23.23 \%$ of female are not satisfied.

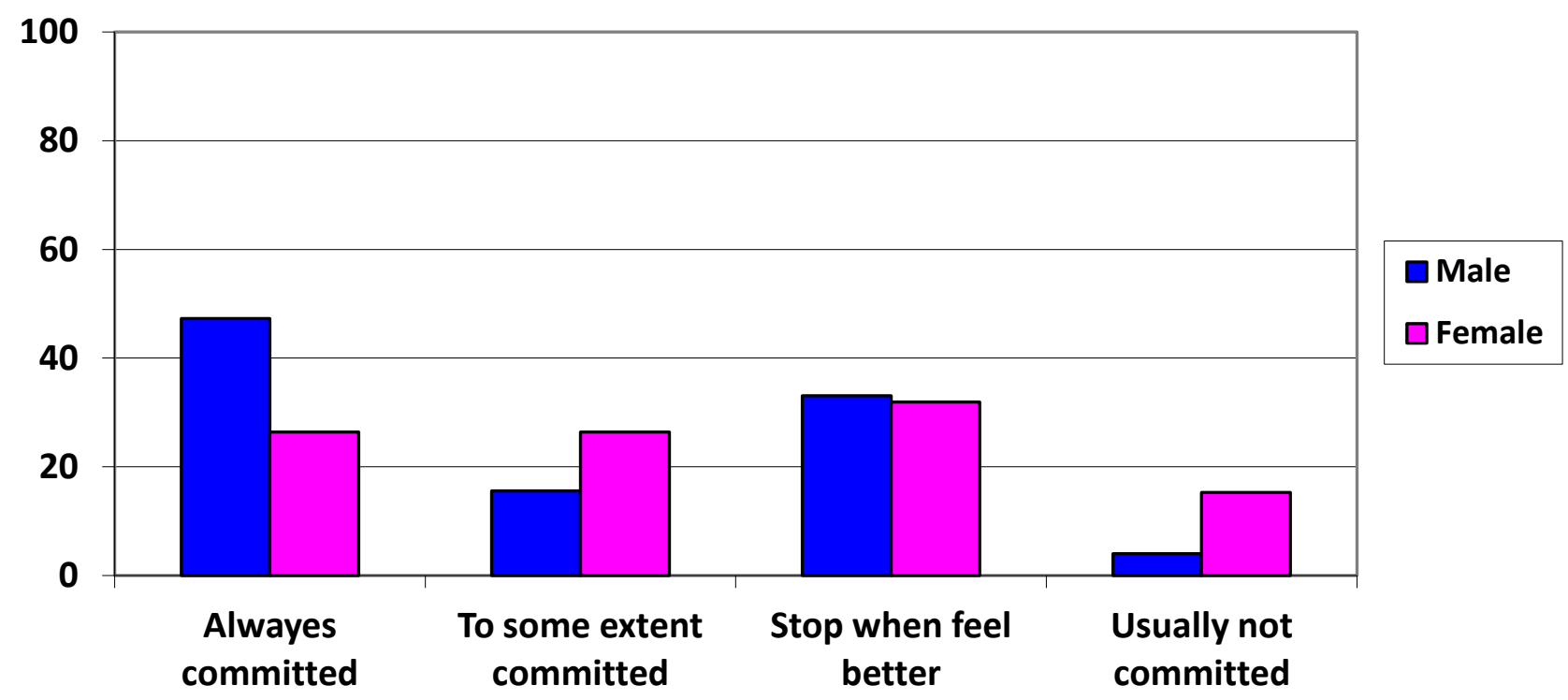

Figure 3:- percentages of compliance to drugs the doctor prescribed by gender.

According to compliance to drugs the doctor prescribed by gender as shown in figure 3, males more committed $47.29 \%$ than females $26.4 \%$ and $15.54 \%$ of males and $26.4 \%$ of females said they committed to some extent and $33.1 \%$ of males and $31.89 \%$ of females said they stop taking medication when they feel better and females more not committed $15.26 \%$ compared to males $4 \%$, this comparison chart are statistically significant $(\mathrm{p}<.001)$. 


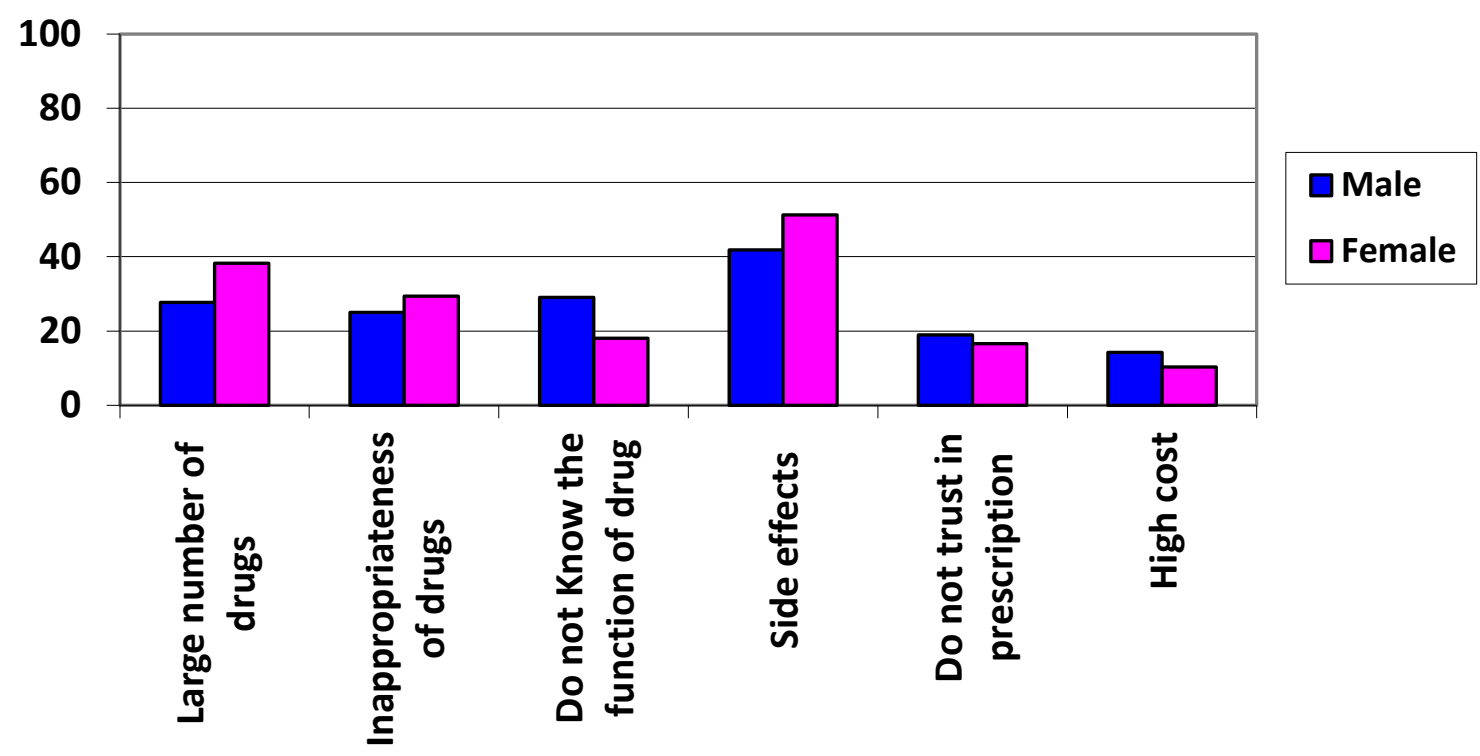

Figure 4:- The opinion of participants of what are the reasons which may lead to failure in compliance with medication by gender.

According to opinion of participant of what are the reasons which may lead to failure in compliance with medication showed that females are more non-compliance to treatment due to large number of drugs $38.3 \%$ compare to males $27.7 \%(\mathrm{p}<.012)$ also due to inappropriateness of drugs $29.4 \%$ compared to males $25 \%, 29.1 \%$ of males said that lack of knowledge about function of drugs contribute to their non-compliance to drugs compared to $18 \%$ of females ( $\mathrm{p}<.04)$, side effects contribute to non-compliance in $41.9 \%$ of males compared to $51 \%$ of females $(\mathrm{p}<.03)$, distrust of doctor prescription contribute to non-compliance in $18.9 \%$ of males compared to $16.6 \%$ of females, high cost of drugs contribute to non-compliance in $14.2 \%$ of males and $10.3 \%$ in females. 


\section{Figure 5:The diseases that patients may stop taking medication for}

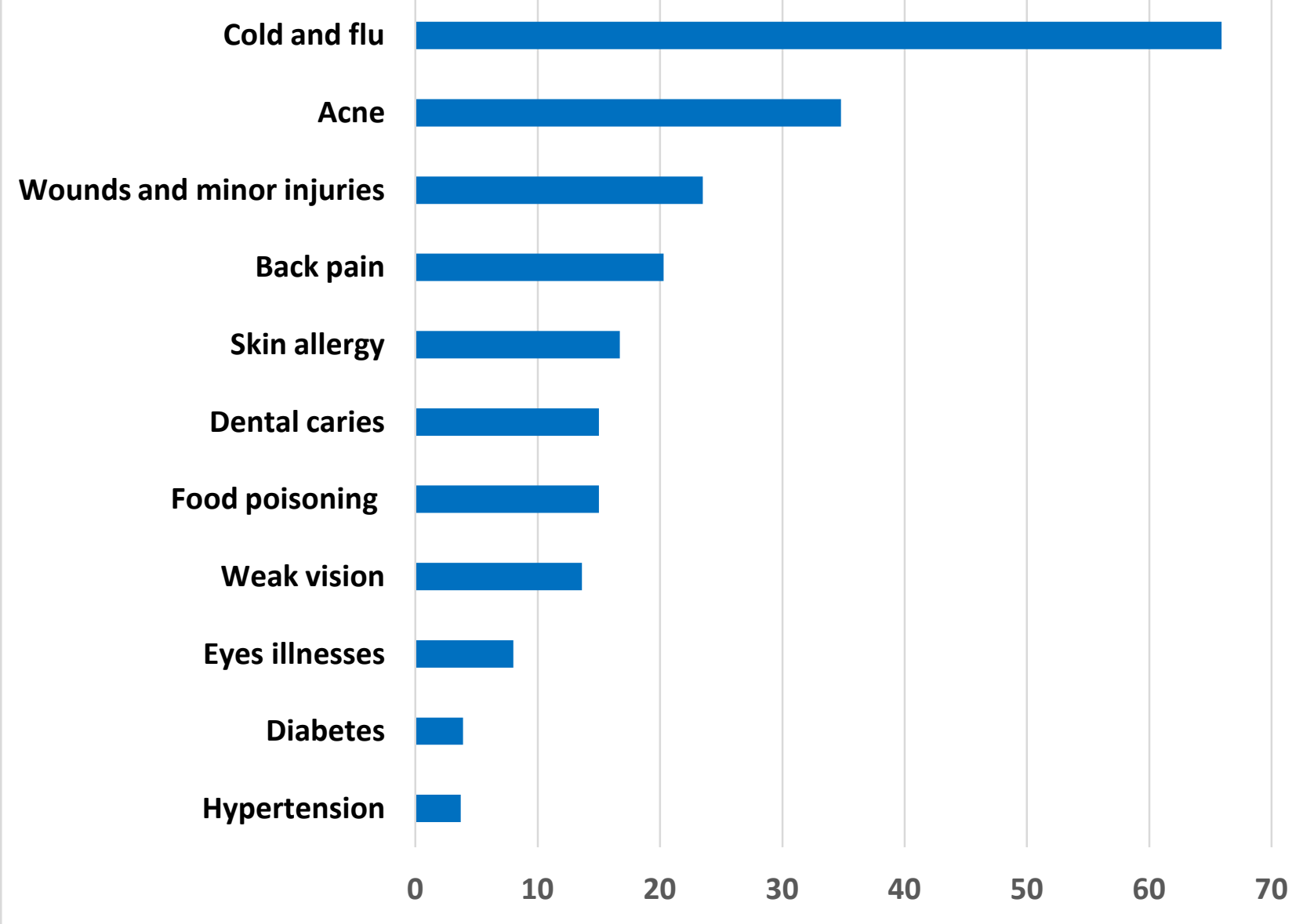

According to above figure 5 showed that $65.9 \%$ of participants said that cold and flu in the top of diseases that they left treatment for followed by Acne $34.8 \%(\mathrm{p}<.002)$, wounds and minor injuries $23.5 \%$, back pain $20.3 \%$, skin allergy $16.7 \%$, dental caries $15 \%$, food poisoning $15 \%$, weak vision $13.6 \%(\mathrm{p}<.029)$,eye illnesses $8 \%$, diabetes $3.9 \%$,hypertension $3.7 \%$.. 


\section{Figure 6:patients' opinion regarding the possible solutions to overcome the non- compliance with medication}

The provision of more health centers

Reduce the prices of medicines

Reduce doses for patients who have multiple diseases

Provide family physician

Good deal with the patient during the visit and give a chance to talk

Clarify the benefits and side effects to the drug

Attention to follow-up between the doctor and the patient by means of modern communication (social media)

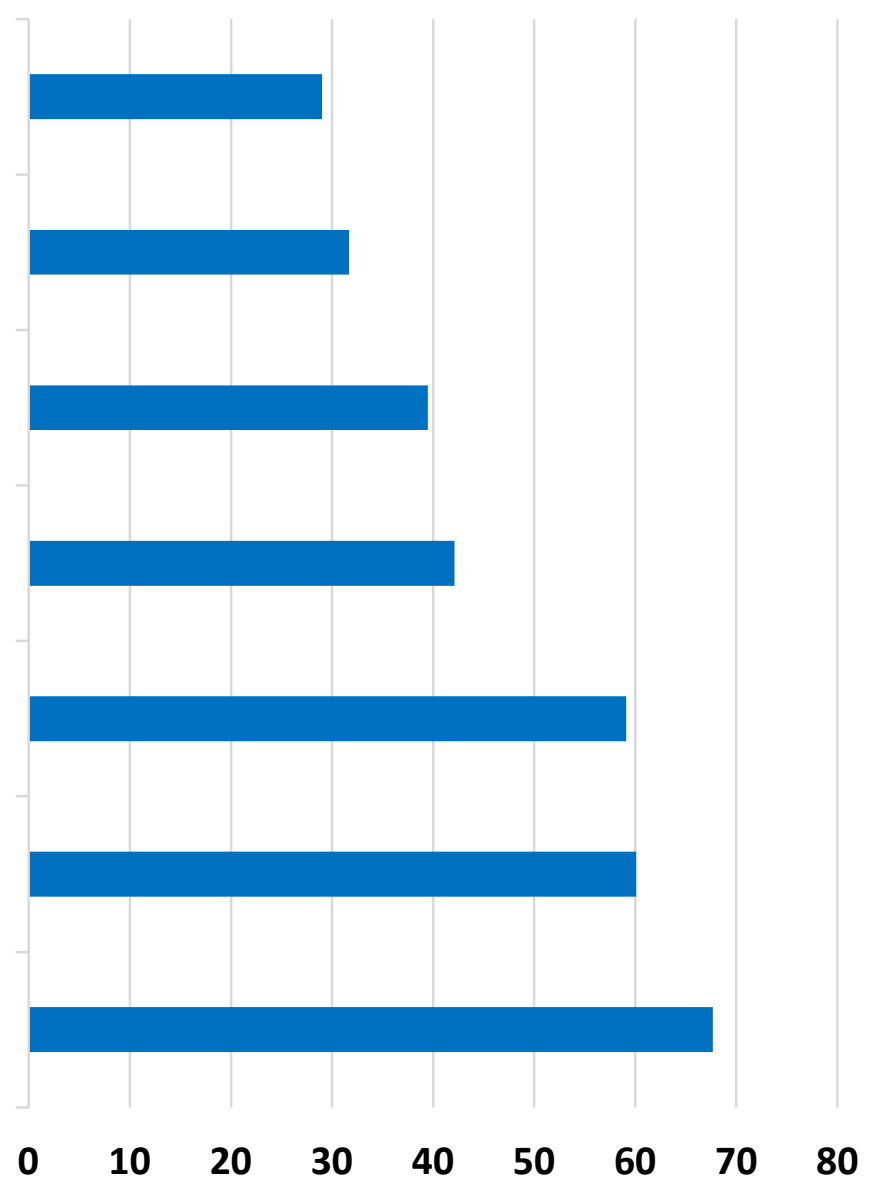

According to patients' opinion regarding the possible solutions to overcome the non-compliance with medication in figure 6 showed to be follow up by social media $67.6 \%$ followed by clarification of side effects $60.1 \%$, give chance to talk $59.1 \%$ ( $\mathrm{p}<.01$, more in males), provide more family physician $42.1 \%$, reduce the number of doses who have multiple diseases $39.5 \%(\mathrm{p}<.001$, more in females), reduce the prices of drugs $31.7 \%(\mathrm{p}<.04$, more in females), provide more health centers $29 \%$. 


\section{Figure 7: satisfaction by health facility}

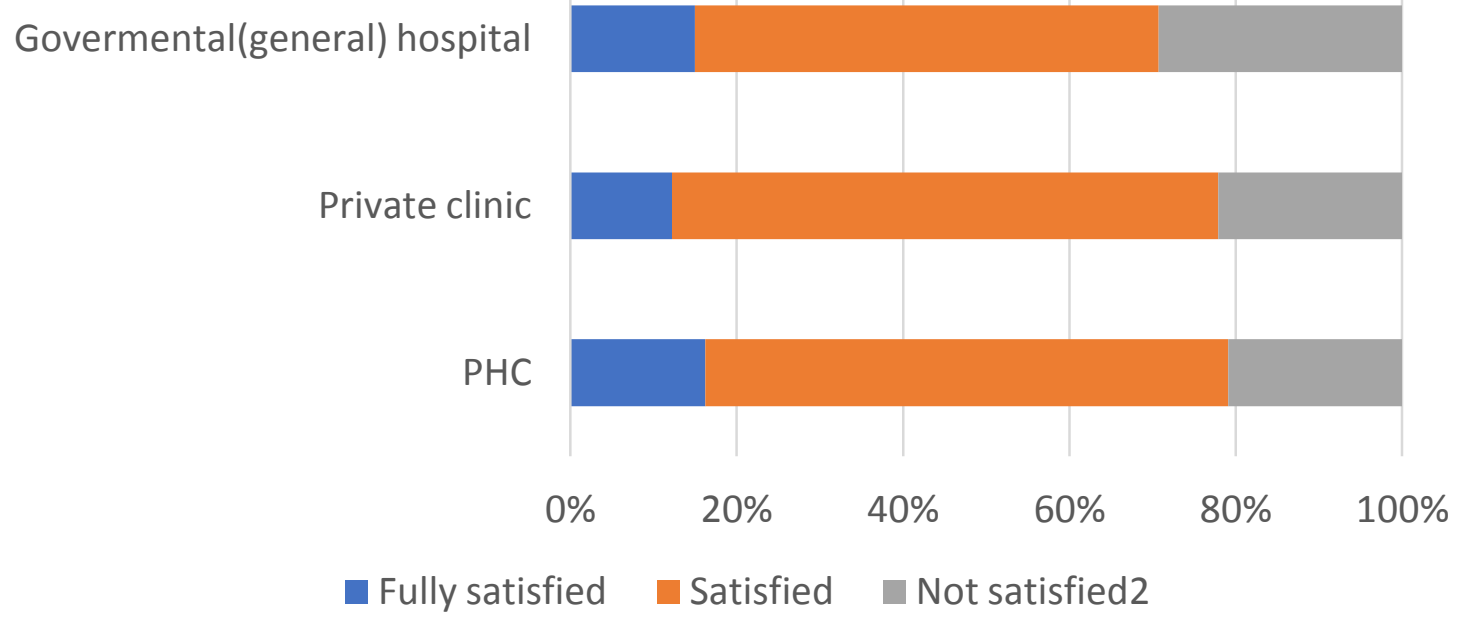

According to satisfaction by health facility in figure 7 showed that the most fully satisfied health facility is PHC (primary health care center) $16.2 \%$ followed by governmental hospital $15 \%$,private clinic $12.2 \%$, private hospital $11.2 \%$ and the most satisfied health facility is private hospital $67.1 \%$ followed by private clinic $65.6 \%$, PHC $62.8 \%$, governmental hospital $55.8 \%$, the most not satisfied health facility is governmental hospital followed by private clinic $22.1 \%$, private hospital $21.7 \%$, PHC $20.9 \%$. 


\section{Figure 8: compliance by health facility}

\section{Govermental (general) hospita}

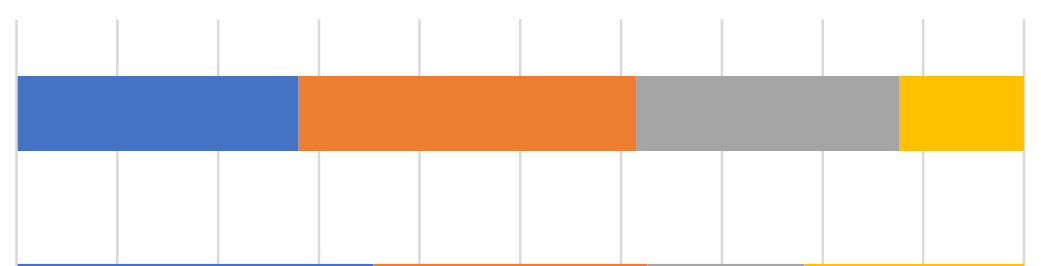

Private hospital

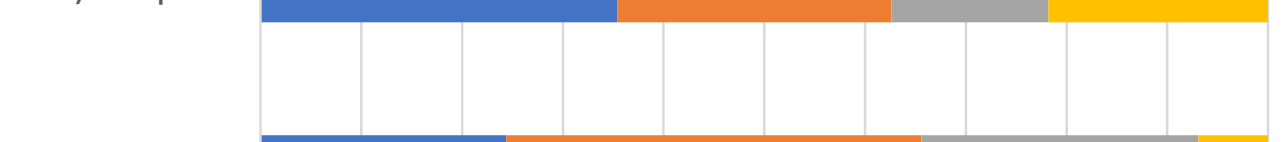

Private clinic
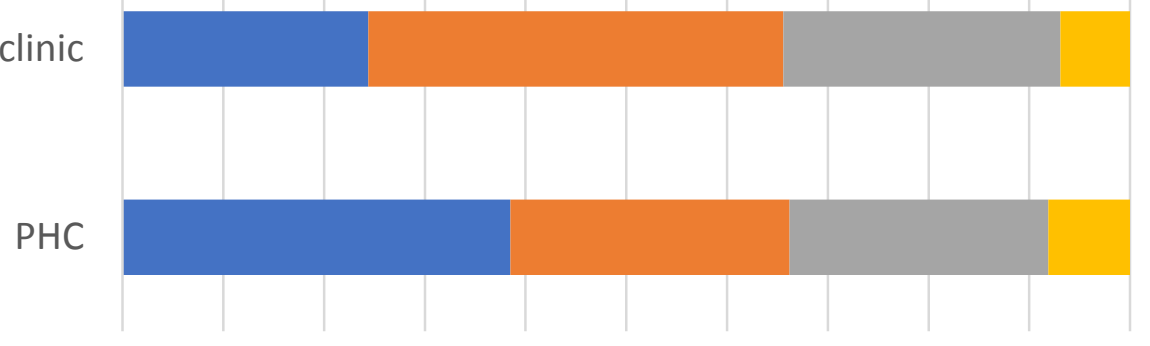

$\begin{array}{llllllllllll}0 \% & 10 \% & 20 \% & 30 \% & 40 \% & 50 \% & 60 \% & 70 \% & 80 \% & 90 \% & 100 \%\end{array}$

Always commited to dugs

stop when feel better

Commited to some extent to drugs $\square$ Not commited to drugs

According to compliance by health facility as shown in figure 8, participants are more compliance to PHC $38.5 \%$ followed by governmental hospital $35.4 \%$, private hospital $28 \%$, private clinic 24.4 and participants stop taking medication prescribed by doctor more in private clinic $41.2 \%$ followed by private hospital $33.5 \%$, PHC $27.7 \%$, governmental hospital $27.5 \%$ and participants committed to some extent to drugs more in PHC $25.7 \%$ followed by private clinic $27.5 \%$, private hospital $26.1 \%$. governmental hospital $15.6 \%$ and the health facility that have high rate of noncompliance to drugs found to be governmental hospital $21.8 \%$ followed by private hospital $12.4 \%$, PHC $8.1 \%$, private clinic $6.9 \%$, this comparison chart are statistically significant $(\mathrm{p}<.001)$.

According to compliance by age we found that people more that 30 years old are the age group with more compliance rate compared to other age groups $(\mathrm{p}<.001)$

Also that particular age group had the higher rate of satisfaction compared to other age groups ( $<<.002)$ 
Table 2:- Participants perception toward compliance to medication.

\begin{tabular}{|c|c|c|c|}
\hline & Number & Percentage & P value \\
\hline $\begin{array}{l}\text { 1- Do you think that the mishandling of the doctor may } \\
\text { be a reason not to trust the physician medical advice and } \\
\text { leave taking medication? } \\
\text { Yes } \\
\text { No } \\
\text { To some extent } \\
\end{array}$ & $\begin{array}{l}302 \\
55 \\
219 \\
\end{array}$ & $\begin{array}{l}51.4 \% \\
11.2 \% \\
37.3 \% \\
\end{array}$ & $<.01 *$ \\
\hline $\begin{array}{l}\text { 2- Which of the following age groups noticed his lack of } \\
\text { medication compliance or rejected? } \\
\text { Children } \\
\text { Teens } \\
\text { Adults } \\
\text { Elderly } \\
\end{array}$ & $\begin{array}{l}268 \\
258 \\
221 \\
235 \\
\end{array}$ & $\begin{array}{l}45.7 \% \\
44 \% \\
37.6 \% \\
40 \%\end{array}$ & $<.1$ \\
\hline $\begin{array}{l}\text { 3- lack of medication compliance may worsen my health } \\
\text { status? } \\
\text { Yes } \\
\text { No } \\
\text { To some extent }\end{array}$ & $\begin{array}{l}245 \\
62 \\
280\end{array}$ & $\begin{array}{l}41.7 \% \\
10.6 \% \\
47.7 \%\end{array}$ & $<.02 *$ \\
\hline $\begin{array}{l}\text { 4- I think that my commitment to the drug may bring me } \\
\text { and other health problems? } \\
\text { Yes } \\
\text { No }\end{array}$ & $\begin{array}{l}212 \\
375 \\
\end{array}$ & $\begin{array}{l}36.1 \% \\
63.9 \% \\
\end{array}$ & $<.3$ \\
\hline $\begin{array}{l}\text { 5- Which of the following health centers commitment to } \\
\text { taking the medication out more? } \\
\text { PHC } \\
\text { Government } \\
\text { Special } \\
\text { Teaching } \\
\text { Private Clinic } \\
\end{array}$ & $\begin{array}{l}78 \\
198 \\
115 \\
36 \\
160\end{array}$ & $\begin{array}{l}13.3 \% \\
33.7 \% \\
19.6 \% \\
6.1 \% \\
27.3 \% \\
\end{array}$ & $<.09$ \\
\hline $\begin{array}{l}\text { 6- Which health facility you visit usually? } \\
\text { PHC } \\
\text { Private Clinic } \\
\text { Government } \\
\text { Special } \\
\end{array}$ & $\begin{array}{l}148 \\
131 \\
147 \\
161\end{array}$ & $\begin{array}{l}25.2 \% \\
22.3 \% \\
25 \% \\
27.4 \%\end{array}$ & $\begin{array}{l}<.01^{*} \\
\text { Male more in } \\
\text { PHC }\end{array}$ \\
\hline $\begin{array}{l}\text { 7- What types of follow-up used by the health facility that } \\
\text { you visit to complete your follow-up? } \\
\text { Telephone } \\
\text { Email } \\
\text { Doctor visit me } \\
\text { Internet \& New social media } \\
\text { No communication outside health facility }\end{array}$ & $\begin{array}{l}101 \\
11 \\
30 \\
52 \\
458\end{array}$ & $\begin{array}{l}17.2 \% \\
1.9 \% \\
5.1 \% \\
8.9 \% \\
78 \%\end{array}$ & $\begin{array}{l}<.001 * \\
<.1 \\
<.3 \\
<.001 * \\
<.001 *\end{array}$ \\
\hline
\end{tabular}




\section{Figure 9 :The reasons that brings health problems despite adherence to medical prescription by gender}

\section{Poor manufacturing quality of medication}

Long waiting list for the next follow up appointment with physician

Lack of follow-up with your doctor about the medicine

Do not think my commitment may cause any health problems

Giving overdoses

Knowledge about medication side effects was not given by physician

Avoid reading the patient file by the physician

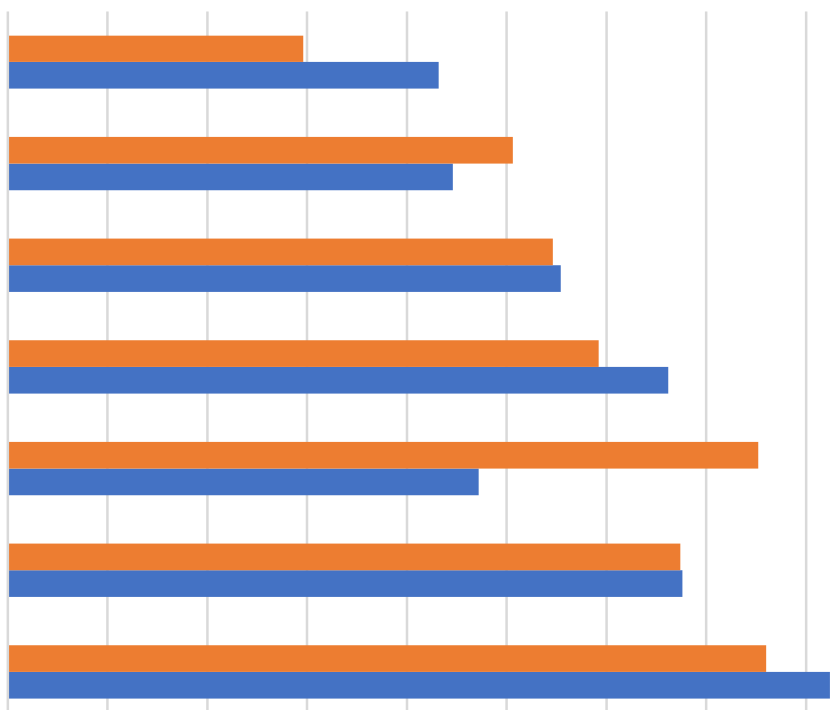

Female $\square$ Male

According to the reasons that brings health problems despite adherence to medical prescription as figure 9 showed, we emphasized significant value which is giving overdoses ( $\mathrm{p}<.002$, more in females) and poor manufacturing quality of medication ( $\mathrm{p}<.03$, more in males)

Table 3: Other related questions for drug compliance .

\begin{tabular}{|c|c|c|c|}
\hline & Number & Percentage & P value \\
\hline $\begin{array}{l}\text { 1- Do you buy drugs from pharmacy without doctor } \\
\text { prescription? } \\
\text { Yes } \\
\text { No }\end{array}$ & $\begin{array}{l}472 \\
115\end{array}$ & $\begin{array}{l}80.4 \% \\
19.6 \%\end{array}$ & $<.005^{*}$ \\
\hline $\begin{array}{l}2 \text {-The presence of health centers near the residential } \\
\text { neighbourhood may reduce non-compliance to drugs? } \\
\text { yes } \\
\text { no } \\
\text { to some extent }\end{array}$ & $\begin{array}{l}99 \\
345 \\
143\end{array}$ & $\begin{array}{l}16.9 \% \\
58.8 \% \\
24.4 \%\end{array}$ & $<.01 *$ \\
\hline $\begin{array}{l}\text { 3- Lack of a commitment with medication are widespread in } \\
\text { the city? } \\
\text { Yes } \\
\text { No } \\
\text { To some extent }\end{array}$ & $\begin{array}{l}245 \\
62 \\
280 \\
\end{array}$ & $\begin{array}{l}41.7 \% \\
10.6 \% \\
47.7 \% \\
\end{array}$ & $<.1$ \\
\hline
\end{tabular}




\section{Discussion:-}

Effects of Compliance: adherence is a very important issue in medical field for many causes so as we know that non-compliance to treatment imposes a considerable financial burden upon health care systems.

\section{Doctor - patient Relationship:-}

A paternalistic approach to be avoided because the doctor patient relationship, And communication and shared decision-making are important factors affecting compliance as shown in our survey that \%51.4(n=302) will not committed to medication if they face misbehavior from their physicians that will affect the relationship between them also Knowing each patient's health beliefs and physician plan are the key feature of the new doctor patient encounter.

\section{Doctor-patient decision Making:-}

We have to discuss the treatment plan where both patient and doctor can adhere, as we know a lot of people in KSA use new social media in communication recently so as we found according to survey that the best option to resolve a medical non- compliance regarding participant opinions showed Good following up between doctor and patient by mean of modern social media 67.6\% $(n=397)$ followed by Explain the benefits and the side effects of medications to patients $60.1 \%(n=353)$, Good behavior between doctor and patient and give the patient chance to talk $59.1 \%(n=347)$ and other causes as mentioned in results, so as we can see the great role of patient in making decision about their treatment the thing that will decrease patient non-compliance, we need to review our style of communication and provide special office only for patient relationship and communication outside health facility because as we see in the result that more than $70 \%$ of health facilities lack these services .

\section{Satisfaction:-}

We need to study "seeing the same physician" as in case of family physician and its influence on patient satisfaction, that reflect the need of family physician in our health system as shown in our study that one of the most important thing to overcome noncompliance is Provide more family physicians $42.1 \%$ where the patients can follow again and again the same physician to complete their health issues and get maximum benefits.

\section{Role of neighbor PHC:-}

According to survey showed that $\% 58.8$ said that availability of neighbor primary health center have no effectiveness in decrease non- compliance, and we conduct study to show which health care facility have more rate of compliance and the result showed that \%33.7 which mean more than $1 / 3$ of participants are more compliant toward governmental hospital followed by private clinic(\%27.3 ), private hospital (\%19.6), PHC(\%13.3), teaching hospital, as we can see governmental hospital goes with highest rate of compliance but we recommended other study to be conducted to see what factors affect compliance in these health facilities.

\section{History of PHC:-}

There was study that have explanation on why PHC it occupies middle place in patient adherence, By the year 1987 the Ministry of Health in Saudi Arabia had established 1477 Primary Health Care centers all over the kingdom, Saudi study done 3, June 1993 [9] was to assess the satisfaction of patients with different aspects of Primary Health Care services in Riyadh, the results showed that the patients are generally moderately satisfied with the services. They are most satisfied with the effectiveness and humaneness aspects of care.

\section{Compliance of general population:-}

Regarding compliance to medication of general population, many research done in KSA but did not mentioned the compliance of general population and most of their research confined to certain group of patient with certain disease, so in our study we have conducted a study to involve the public and we found that most of responses $32.2 \%$ said they stop taking medication if they felt better, while $31.7 \%$ said they always committed to the drugs that prescribed by the doctor, $23.7 \%$ said Sometimes , $12.4 \%$ will never committed to the drugs that prescribed by the doctor, so here we can see that more than $1 / 3$ of participants stop taking medication if they feel better that indicate poor knowledge about side effect of some drugs like antibiotics and the risk of development of bacterial resistance as result of that, as we consider our participants highly educated despite we found higher rate of noncompliance to treatment the thing that imposes serious attention. According to our study \%65.5 stop taking medication in flu and cold (that sometimes may need antibiotic prescribed by GP). 
Relationship between education level and compliance:-

As we mentioned before that higher educational levels of participants were found to be $\% 32.2$ stop when they feel better, Several studies have found association between higher education level and compliance,[10] while some studies have found no such association, A study conducted in the UK has shown that patients with a lower level of education have better compliance.[11,12] It may be presumed that patients with a lower educational level may have more trust in the physician's advice. However, these results show that education may not be a good predictor of therapeutic

compliance.

Causes of non-compliance among general population of eastern province:-

Our study and other studies shown many causes of non-compliance, in our study we found many causes e.g., the large number of drugs that must be taken, Inappropriateness of medication, lack of knowledge about the function of drugs, Side effects, lack of trust in doctor prescription, high cost of medications and other studies conducted in KSA shown other causes [13], Those patients who did not get adequate information on what to do in the event of their missing a dose, or if they experienced any side effects of the medicine, were more non-compliant.

Numerous researches involving:-

Various diseases have evaluated the effect of the patient- physician relationship on patients' compliance, and has found it to be another strong factor in favor of patient compliance. [14-16], Compliance to treatment advice was good when the physicians were supportive, supplied vital information, and listened patiently to patients [17].

Suggested solutions to overcome non-compliance among general population of eastern province:

The best option to overcome medical non- compliance regarding participants opinions showed to be following up between doctor and patient by modern social media $67.6 \%(n=397)$, Explain the benefits and the side effects of medications $60.1 \%(n=353)$, Good behavior between doctor and patient and give the patient chance to talk $59.1 \%$ $(n=347)$, Provide more family physicians $42.1 \%(n=247)$, Reduce the doses of patients who have a lot of diseases $39.5 \%(n=232)$, Reduce the prices $31.7 \%(n=186)$, provide more Health Centers $29 \%(n=170)$.

\section{Conclusion:-}

The findings show that males and people at age of 30 more compliance to drugs and more satisfied, side effect and accumulated drugs are the common cause of non-compliance, best option to overcome non-compliance found to be follow up by social media and explain side effects of drugs, people less satisfied with governmental hospital and more compliance to PHC so there are a definite need for Hight qualified health system, patient -centered relationship, health education and to improve patient-doctor communication and health services.

\section{Acknowledgments:-}

Department of family and community medicine at abdurahman bin faisal university .

\section{References:-}

1. Partridge AH, Avorn J, Wang PS, Winer EP. Adherence to therapy with oral antineoplastic agents. J Natl Cancer Inst 2002; 94:652-61.

2. Jing J, Sklar GE, Min Sen Oh V, Chuen LiS. Factors affecting therapeutic compliance: A review from the patient's perspective. Ther Clin Risk Manag 2008;4:269-86

3. Roter DL, Stewart M, Putnam SM, Lipkin M, Stiles W, Inui TS. Communication patterns of primary care physicians. JAMA 1997;227:350-56.

4. Kaplan SH, Greenfield S, Ware JE. Assessing the effects of physician-patient interactions on the outcomes of chronic disease. Med Care 1989;27:S110-27.

5. SM. Which facets of communication have strong effects on outcome- a meta analysis. Communication with medical Patients. Sage Publications. 1989.

6. Al-Shammari SA, Khoja T, Al-Yamani MJ. Compliance with short-term antibiotic therapy among patients attending primary health center in Riyadh, Saudi Arabia. J Royal Soc Promot Health 1995;115:231-4.

7. Al-Sowielem LS, Elzubier AG. Compliance and knowledge of hypertensive patients attending PHC centers in Al-Khobar, Saudi Arabia. East Mediterr Health J 1998;4:301-7. 
8. Abula T, Worku A. Patient noncompliance with drug regimens for chronic diseases in northeast Ethiopia. Ethiop J Health Dev 2001;15:185-92

9. Mansour AA, Al-Osimy MH. A study of satisfaction among primary health care patients in Saudi Arabia. Journal of Community Health. 1993;18(3):163-73.

10. Ghods A, Nasrollahzadeh D. Noncompliance With Immunosuppressive Medications After Renal Transplantation. Tissue Antigens. 2002;60(6):553.

11. Kyngas $\mathrm{H}$, Lahdenpera $\mathrm{T}$. Compliance of patients with hypertension and associated factors. $J$ Ad Nurs 1999;29:832-9.

12. Senior V, Marteau TM, Weinman J. Self-Reported Adherence to Cholesterol-Lowering Medication in Patients with Familial Hypercholesterolaemia: The Role of Illness Perceptions. Cardiovascular Drugs and Therapy. 2004;18(6):475-81.

13. Khan AR, Al-Abdul Lateef ZN, Al Aithan MA, Bu-Khamseen MA, Al Ibrahim I, Khan SA. Factors contributing to non-compliance among diabetics attending primary health centers in the Al Hasa district of Saudi Arabia. J Fam Community Med 2012;19:26-32.

14. Hernández-Ronquillo L, Téllez-Zenteno JF, Garduño-Espinosa J, González-Acevez E. Factors associated with therapy noncompliance in type-2 diabetes patients. Salud Publica Mex 2003;45:191-7.

15. Cummings KM, Kirscht JP, Binder LR, Godley AJ. Determinants of drug treatment maintenance among hypertensive persons in inner city Detroit. Public Health Rep 1982;97:99-106.

16. Kim YS, Sunwoo S, Lee HR, Lee KM, Park YW, Shin HC, et al. Determinants of non-compliance with lipidlowering therapy in hyperlipidemic patients. Pharmacoepidemiol Drug Saf 2002;11:593-600.

17. Lawson VL, Lyne PA, Harvey JN, Bundy CE. Understanding why people with type 1 diabetes do not attend for specialist advice: A qualitative analysis of the views of people with insulin-dependent diabetes who do not attend diabetes clinic. J Health Psychol 2005;10:409-2. 